\title{
A Terapia Ocupacional e as ações na educação: aprofundando interfaces*
}

\section{The Occupational Therapy and the actions in the education: deepening interfaces}

\author{
Eucenir Fredini Rocha ${ }^{1}$
}

ROCHA, E. F. A Terapia Ocupacional e as ações na educação: aprofundando interfaces. Rev. Ter. Ocup. Univ. São Paulo, v.18, n. 3, p. 122-127, set./dez. 2007.

\begin{abstract}
RESUMO: Objetivo: Contribuir para a reflexão sobre a construção da atuação da Terapia Ocupacional no campo da educação. Apresenta considerações sobre abordagens da Terapia Ocupacional, em diferentes paradigmas, ressaltando a vinculação das ações terapêuticas ocupacionais às premissas da educação especial e às do movimento internacional de inclusão social. Propõe um deslocamento da perspectivas da educação especial, com a rejeição por completo do conceito de "Integração Social" e da problematização do conceito de "Inclusão" para a elaboração de propostas de Terapia Ocupacional na Educação. Entende, assim, que as contribuições da Terapia Ocupacional no campo da educação devem visar uma práxis inspirada na busca das paixões alegres, a partir de um compromisso éticopolítico com o sofrimento do outro, como coloca Espinosa, onde o processo de construção de uma positividade da inclusão social pode se dar de diferentes formas, apresentadas de modo propositivo no texto.
\end{abstract}

PALAVRAS-CHAVE: Terapia ocupacional e educação. Inclusão escolar. Integração escolar. Terapia ocupacional. Inclusão escolar.

\footnotetext{
* Este trabalho foi apresentado parcialmente no X Congresso Brasileiro de Terapia Ocupacional - Goiânia/2007.

1. Mestre em Psicologia Escolar e Doutora em Psicologia Social. Docente do Departamento de Fisioterapia, Fonoaudiologia e Terapia Ocupacional da FMUSP.

Endereço para correspondência: eucenir@usp.br
} 


\section{APRESENTAÇÃO}

$\mathrm{T}$ Trata-se de uma reflexão construída a partir de experiências práticas (ROCHA, 1999, 2003, 2006) orientadas por princípios da ética de Espinosa (ESPINOSA, 1979) ${ }^{(1)}$ sobre a construção da atuação da Terapia Ocupacional no campo da Educação. Tomamos como ponto de partida duas questões recorrentes: a Educação é um campo de intervenção da Terapia Ocupacional? Que ações são próprias de Terapia Ocupacional na Educação?

Historicamente, a inserção da Terapia Ocupacional no campo da Educação se fez através da chamada "Educação Especial", voltada para pessoas com deficiências, em instituições educacionais especializadas, segregadas da rede regular de ensino, ou ainda, do trabalho desenvolvido nas denominadas "classes especiais" dirigidas a populações específicas: estudantes com deficiência mental, física, visual, auditiva ou transtorno do desenvolvimento.

Em geral, o trabalho da Terapia Ocupacional nesse contexto educacional se caracteriza/ou pelas atividades de apoio aos educadores com uma ação voltada especificamente para o estudante com deficiência, através de procedimentos terapêuticos organizados sob os critérios de diagnósticos clínicos ou psico-pedagógicos, avaliação de comportamento, critérios de faixa etária, entre outros.

Os espaços educacionais especiais surgem no Brasil no século XIX e ganham legitimidade da metade do século $\mathrm{XX}$ em diante, apoiados nas estruturas das instituições de reabilitação especializadas, organizadas com bases no modelo biomédico, que consideram as pessoas com deficiências como portadoras de desvios da normalidade.

Assim, a base do trabalho de Terapia Ocupacional no campo da "Educação Especial" se constituiu como uma extensão da atividade clínica desenvolvida nos serviços de reabilitação, que busca a normatização do comportamento, do desempenho motor-funcional e do desenvolvimento cognitivo.

A finalidade da intervenção é a integração social, paradigma fortemente influenciado pelos serviços especializados de reabilitação da década de 50 em diante (ROCHA, 2006) e supõe uma compreensão da inserção social da pessoa com deficiência focada no seu esforço pessoal e individual.
Nessa perspectiva, a ação da Terapia Ocupacional aloca um conjunto de esforços reabilitacionais dirigidos ao indivíduo, a fim de proporcionar o desenvolvimento de habilidades e competências da pessoa com deficiência para a sua adaptação ao meio educacional e social. Ou seja, a finalidade da intervenção recai somente sobre o indivíduo, visando minimizar as conseqüências de suas incapacidades, e, conseqüentemente, desencadear a inserção da pessoa com deficiência no meio escolar e social.

Aqui, o indivíduo é responsabilizado pelo sucesso ou fracasso de seu empreendimento, e a imagem correspondente é do deficiente como herói, quando obtém sucesso, ou do coitadinho quando fracassado. Não é um acaso que a maioria dos espaços escolares de educação especial estavam/estão ${ }^{(2)}$ vinculados a instituições de reabilitação de caráter filantrópico.

Da década de 80 para cá, o movimento internacional de inclusão social (SASSAKI, 1997), que congrega pessoas com deficiências, profissionais e a sociedade civil de uma forma geral, propõe o redirecionamento dessa finalidade. Nessa nova abordagem o paradigma de apoio indica uma "sociedade de suportes", ou seja, uma sociedade responsável por todos os seus membros, com mecanismos que propiciem o acolhimento de forma indiscriminada, com possibilidades efetivas para a participação de todos.

O paradigma da inclusão social das pessoas com deficiências supõe a adequação da coletividade. Há, portanto, a preconização imperativa do ajuste social na direção da inclusão de todos, o foco deixa de ser o indivíduo e passa a ser o coletivo. Nessa abordagem ainda predomina o conceito de "normatização", não mais do sujeito com deficiência através da correção de suas incapacidades, mas da adequação do coletivo, compreendido como os espaços sociais, as leis, o ambiente urbano, o comportamento relacional e posturas políticas corretas.

Ainda na década de 80 , com o processo de redemocratização do país, o movimento de pessoas com deficiências ganhou visibilidade social e política, que culminou com a nova Lei de Diretrizes Básicas para a Educação. Considerando, ainda, o direito de acesso à Educação na rede regular de ensino, a demanda reprimida desse segmento populacional passou a exigir vagas.

\footnotetext{
(1) Consultar Ética III: "Da origem e da natureza das afecções”. Como o objetivo do artigo não é discutir os princípios da ética de Espinosa, remetemos o leitor interessado ao Posfácio do livro "Reabilitação de Pessoas com Deficiência" (Rocha, 2006) e para um aprofundamento filosófico indicamos como literatura introdutória textos de Marilena Chauí $(1987,1995)$.

(2) A proposta de educação especial ainda predomina em nosso país, patrocinada, principalmente, pelas entidades assistenciais filantrópicas.
} 
A prática da Terapia Ocupacional até então restrita aos espaços institucionais da Educação Especial é desafiada a reinventar sua intervenção, passa a desenhar novos contornos; grupos de terapeutas ocupacionais propõem a intervenção no campo do ensino regular tomando como objeto de estudo as metodologias empregadas nos processos de ensino-aprendizagem. Acontece, então, um primeiro deslocamento, o objeto de intervenção deixa de focar as deficiências e incapacidades do indivíduo para analisar as dificuldades e limites das diferentes abordagens de ensinoaprendizagem que levam em conta as diversas formas de entender o desenvolvimento humano.

A literatura sobre Terapia Ocupacional passa a produzir reflexões sobre as abordagens de caráter construtivista (piagetiana) (BARTOLOTTI; DE CARLO, 2001; AMARO, 2006) e histórico-cultural (BARTOLOTTI; DE CARLO, 2001; MUNGUBA, 2007). Nessa perspectiva, as ações da Terapia Ocupacional na Educação confundem-se com a dos educadores em suas estratégias, e tal confusão agravase pelo fato de que o terapeuta ocupacional não tem uma formação específica em relação ao conteúdo pedagógico. A proposta de ação da Terapia Ocupacional na Educação torna-se ainda mais difícil se considerarmos a complexidade da realidade educacional em nosso país, com professores muitas vezes despreparados, classes com um grande número de estudantes e uma falta crônica de infra-estrutura nas escolas.

Em outra direção autores como Jurdi et al. (2004) e Costabile e Brunello (2005) propõem ações no contexto escolar a partir de reflexões sobre o cotidiano e possibilidades de ações grupais e lúdicas junto aos educadores e estudantes. Aqui é sugerido outro deslocamento do objeto de intervenção da terapia ocupacional; a ação passa a incidir no contexto do cotidiano, dos significados atribuídos às atividades e da superação das dificuldades relacionais emergidas com a presença de estudantes com ou sem deficiência. O objeto no qual ocorrem as intervenções adquire conotação de um sujeito coletivo, ou seja, o espaço escolar e suas relações.

\section{Do paradigma da "normatização" à problematização da inserção escolar de pessoas com deficiência}

Considerando a necessidade de romper com o paradigma da "normatização", seja do corpo, seja do comportamento, das metodologias pedagógicas ou das organizações e relações sociais como premissa para o trabalho da Terapia Ocupacional na Educação, propomos, primeiramente, a rejeição por completo do conceito de "Integração Social" e da problematização do conceito de
"Inclusão" (ROCHA, 2003) para a elaboração de propostas de intervenção nessa área.

O fenômeno da "Inclusão Social" não é desprovido de conflitos, contradições, situações complexas que trazem no bojo de sua gênese os mecanismos próprios da exclusão social. Torna-se, portanto, necessária a explicitação da relação dialética exclusão/inclusão, como coloca Sawaia (1999):

"A sociedade exclui para incluir e esta transmutação é condição da ordem social desigual, o que implica o caráter ilusório da inclusão. Todos estamos inseridos de algum modo, nem sempre decente e digno, no circuito reprodutivo das atividades econômicas, sendo a grande maioria da humanidade inserida através da insuficiência e das privações, que se desdobram para fora do econômico". (p. 8).

Introduz-se aqui a ética e a subjetividade nas análises para além do contexto "macro" dos problemas relacionados à exclusão/inclusão, considerando as histórias dos indivíduos ou dos grupos sociais que vivem cotidianamente situações de sofrimento, abandono, discriminação, injustiças, enfim, diversas modalidades e configurações da exclusão.

Assim, a realidade das pessoas com deficiências e excluídas da rede regular de ensino, matriculadas nas escolas especiais, e/ou que vivem situações de segregação familiar, internadas em suas próprias casas ou inseridas de forma perversa nas escolas regulares, tem que ser consideradas.

Concordamos com Sawaia (1999) que a exclusão deve ser entendida como um processo complexo, com diferentes qualidades, com diferentes expressões (individual/coletiva, subjetiva/objetiva, racional/emocional, relacional/pessoal), não simplesmente como uma falha do sistema que deve ser combatida e sim como um produto do seu funcionamento. Não se trata, portanto, de um fenômeno que através da conscientização das pessoas se transformaria. Enfim, um fenômeno multifacetado com diferentes configurações e expressões, nos indivíduos ou nos grupos, com aspectos emocionais e afetivos envolvidos e com diferentes possibilidades de sofrimento em relação ao tema da exclusão.

Assim, ao falar de exclusão, "fala-se também de desejo, temporalidade e de afetividade, ao mesmo tempo que de poder, de economia e de direitos sociais" (SAWAIA, 1999, p. 98). E, do nosso ponto de vista, consideramos também a necessidade de rever as possíveis formas de intervenção, criando novos modos, novos desenhos de ações, capazes de superar as propostas de conscientização e de convencimento, que visam comportamentos "corretos" em relação às pessoas com deficiências. 
Compreendemos os mecanismos de exclusão como manifestações carregadas de emoções, como o medo diante do desconhecido, de preconceitos e de outras dificuldades vividas no cotidiano por diversas pessoas, com deficiências ou não, que quando explicitadas podem possibilitar mecanismos de superação das limitações diante do novo e do difícil.

Portanto, o desvelamento dos diferentes sentidos que a deficiência adquire para os envolvidos, a desconstrução de um imaginário supersticioso em relação à deficiência e às diferenças podem ser chaves para superação dos processos de exclusão social e escolar necessárias para o desenvolvimento de relações centradas no sujeito coletivo, aqui entendido na complexidade das relações sociais, e na sua capacidade de autodeterminação.

Entendemos que as contribuições da Terapia Ocupacional no campo da Educação devem visar uma práxis inspirada na busca das paixões alegres, a partir de um compromisso ético-político com o sofrimento do outro, como coloca Espinosa.

Portanto, a ação da Terapia Ocupacional na escola não é clínica, nem voltada a aspectos específicos dos estudantes com deficiência, tampouco de convencimento para atitudes corretas e, muito menos direcionada a rever questões pedagógicas e sim, um trabalho a ser desenvolvido com os educadores $^{(3)}$, os estudantes, os familiares e a comunidade, com a finalidade de facilitar apropriação das dificuldades, dos sentimentos, das emoções que permeiam o relacionamento destes com a proposta de inclusão, desvelando, assim, os sentidos que a deficiência tem para todos e construindo relações que potencializem pensamentos e ações centradas na força da coletividade.

Por isso desvelar não é um ato de conscientização, mas uma ação de decomposição das paixões tristes e da composição de paixões alegres por meio de bons encontros que aumentem a potência de pensar e agir, nos quais professores, pessoas com deficiência, família, comunidade e sociedade são objetos e sujeitos dessa nova produção, em direção à redefinição de novas relações com a escola, a deficiência e a inclusão social.

Esse processo de construção de uma positividade da inclusão escolar pode se dar de diferentes formas.

À Terapia Ocupacional cabe a utilização de seus diferentes recursos tecnológicos, não como um fim em si mesmos, mas como um meio capaz de potencializar a construção de novas relações, propondo, de forma objetiva, no cotidiano, o desmonte dos empecilhos aparentes da inclusão escolar, como tipo e gravidade da deficiência, ausência de comunicação verbal, dificuldades cognitivas, entre outras que aparecem em encontros com educadores quando o tema é inclusão escolar de pessoas com deficiências em salas de ensino regular.

Portanto, a meta da Terapia Ocupacional, no espaço escolar, é o fortalecimento da potência de pensar e agir dos sujeitos envolvidos, facilitar a construção de soluções para os impasses a partir do próprio grupo, redirecionando e alocando recursos tecnológicos, sociais e políticos dos equipamentos da comunidade.

\section{Terapia Ocupacional e as ações no contexto da educação}

Entendemos que a Educação é um dos campos de intervenção da Terapia Ocupacional, caracterizado fundamentalmente pela interdisciplinaridade e o seu objeto é o sujeito coletivo, ou seja, os educadores, os estudantes com ou sem deficiência, os equipamentos escolares, os familiares e a comunidade. Cabe, no entanto, a explicitação das finalidades da intervenção da Terapia Ocupacional aos diferentes sujeitos, bem como a organização de ações apropriadas, que considerem o fortalecimento da potência de todos os envolvidos no trabalho.

Com os educadores o objetivo deve ser direcionado ao aparecimento das dificuldades relacionais decorrentes de conteúdos afetivos e das emoções desencadeadas pela presença de pessoas com deficiências, em explicitar as potencialidades e necessidades desses estudantes e em apoiar as atividades coletivas, envolvendo a todos. Como ações da Terapia Ocupacional propõem reuniões com os educadores para a discussão de temas relativos à presença do estudante com deficiência no contexto escolar através de oficinas, de palestras, de atividades psicodramáticas, entre outras possibilidades de construção de diálogos e trocas.

Pode-se ainda objetivar a elaboração de material teórico de apoio aos professores, a socialização de conhecimentos específicos que permitam o re-conhecimento das crianças com deficiências e de suas necessidades, a construção e/ ou sugestão de encaminhamentos para serviços de saúde e de reabilitação.

No trabalho dirigido aos estudantes, apoiar e subsidiar a inserção daqueles que tem deficiência nas escolas, através de tecnologias específicas que facilitem o deslocamento

(3) Consideramos educadores todos aqueles envolvidos diretamente no processo educacional escolar, como funcionários administrativos, de limpeza, professores, coordenadores pedagógicos e diretores. 
e acesso aos diferentes espaços, a adequação do material didático de acordo com as necessidades específicas de cada estudante, a adaptação das atividades escolares e a participação nas diferentes atividades educacionais. Nesse contexto, as ações podem estar circunscritas à elaboração de adaptações, de dispositivos tecnológicos facilitadores do processo educacional como material de leitura e escrita, equipamentos e/ou materiais de auxílio nas atividades de higiene, de alimentação, lúdicas e esportivas, entre outras.

Entre outras intervenções podemos citar: 1) a adequação postural das crianças com deficiência física através de adaptações em cadeiras comuns ou de rodas para as atividades educativas; 2) o acompanhamento do uso de muletas, bengalas e andadores nos diferentes espaços escolares; 3 ) o estudo da necessidade das salas de informática em relação à adequação de programas e equipamentos adaptados para o uso das pessoas com diferentes tipos de deficiência (visual, auditiva, física, mental); 4) a introdução da comunicação alternativa ou suplementar. Essas atividades podem e devem ser acompanhadas pelos serviços de saúde responsáveis pelo tratamento clínico dessas pessoas.

Em relação à direção da escola é possível subsidiar projetos de adequação e conforto ambiental considerando os princípios técnicos para a eliminação das barreiras arquitetônicas, a criação de brinquedos inclusivos e mobiliários adequados, bem como articular propostas junto a outros recursos da comunidade, seja equipamentos de saúde, lazer, trabalho etc.
Com os familiares e com a comunidade facilitar a criação de encontros ou organização de grupos que possam discutir situações, problemas e encaminhamentos relacionados à inserção dos estudantes com deficiência no processo educativo e na constituição de diferentes apoios comunitários.

Ainda em relação às atividades com a comunidade, a Terapia Ocupacional pode contribuir com estudos do território onde o equipamento escolar se insere, detectando recursos e possibilidades de parcerias para os projetos educativos de estudantes com deficiência ou não, bem como a detecção de recursos de saúde e de reabilitação que possam desenvolver parcerias com as escolas.

\section{À guisa de concluir}

A atuação da Terapia Ocupacional na Educação é uma área recente e necessita de acompanhamento e avaliação de diferentes experiências, ampliação do diálogo com diferentes campos de saberes, a fim de que as ações, os procedimentos, enfim, a tecnologia ${ }^{(4)}$ apropriada possa ser testada, sistematizada e socializada.

Cabe, no entanto, ressaltar, que a tecnologia a ser organizada não responde por si só a pergunta se a educação é um campo de intervenção próprio da Terapia Ocupacional, pois os recursos devem ser elaborados nos espaços interdisciplinares e se deve considerar, portanto, a finalidade da intervenção.

ROCHA, E. F. A The Occupational Therapy and the actions in the education: deepening interfaces.

Rev. Ter. Ocup. Univ. São Paulo, v.18, n. 3, p. 122-127, set./dez. 2007.

\begin{abstract}
Objective: To contribute with reflection on the construction of the performance of the Occupational Therapy in the field of education. It presents considerations on the approach of Occupational Therapy, in different paradigms, pointing out the connection of the occupational therapeutical actions to the premises of the special education and to the ones of the international movement of social inclusion. It proposes a dislodging of the perspective of the special education, with the of the concept rejection of "Social Integration" as a whole and of the discussion of the concept of "Inclusion" to elaborate proposals of Occupational Therapy in Education. It thus understands that the contribution of the Occupational Therapy in the field of education must aim at a praxis inspired by the search of the glad passions, from the ethical-political commitment with the suffering of the other, as it places Espinosa, where the process of the construction of a positivity of the social inclusion can be in different forms, presented in propositive ways on the text.
\end{abstract}

KEY WORDS: Occupational therapy and education. Pertaining to school inclusion. Pertaining to school integration. Occupational therapy and pertaining to school inclusion.

\footnotetext{
${ }^{(4)}$ Compreendemos aqui tecnologias como organização de sistemas de comunicação, de locomoção e de transporte, sensibilização e capacitação de recursos humanos, organização de espaços públicos acessíveis, disponibilização de equipamentos e dispositivos de ajuda, construção de redes de serviços de saúde e reabilitação e de outros recursos de apoio na comunidade.
} 
ROCHA, E. F. A Terapia Ocupacional e as ações na educação. Rev. Ter. Ocup. Univ. São Paulo, v.18, n. 3, p.122-127, set./dez. 2007.

\section{REFERÊNCIAS}

AMARO, D. G. Educação inclusiva, aprendizagem e cotidiano escolar. São Paulo: Casa do Psicólogo, 2006.

BARTAlOtTI, C. C.; DE CARLO, M. M. R. do P. Terapia ocupacional e os processos socioeducacionais. In: DE CARLO, M.M.R.do P.; BARTALOTTI, C. C. (org.). Terapia ocupacional no Brasil: fundamentos e perspectivas. São Paulo: Plexus Editora, 2001.

CHAUÍ, M. Sobre o medo. In: CARDOSO, S., et al. Os sentidos da paixão. São Paulo: Companhia da Letras, 1987. p.35-75.

CHAUÍ, M. Espinosa: uma filosofia da liberdade. São Paulo: Editora Moderna, 1995.

COSTABILE, C.; BRUNELLO, M. I. B. Repercussões da inclusão escolar sobre o cotidiano de crianças com deficiência: um estudo a partir do relato das famílias. Rev. Ter. Ocup. Univ. São Paulo, v. 16, n. 3, p. 124-130, 2005.

ESPINOSA, B. Ética: In: Coleção Os Pensadores. Tradução e notas de Marilena Chauí Berlinck. São Paulo: Nova Cultural, 1979.

JURDI, A. P. S, et al. Terapia Ocupacional e propostas de inter- venção na rede pública de ensino. Rev. Ter. Ocup. Univ. São Paulo, v. 15, n. 1 p.26-32, 2004.

MUNGUBA, M. C. Inclusão escolar. In: CAVALCANTI, A.; GALVÃO,C. (org.). Terapia ocupacional: fundamentação \& prática. Rio de Janeiro: Guanabara Koogan, 2007.

ROCHA, E. F. Do corpo orgânico ao corpo relacional: uma proposta de deslocamento dos fundamentos e práticas de reabilitação da deficiência. São Paulo, 1999. Tese (doutorado). Instituto de Psicologia da Universidade de São Paulo.

ROCHA, E. F., et al. Reflexões sobre as possíveis contribuições da terapia ocupacional nos processos de inclusão escolar. Rev. Ter. Ocup. Univ. São Paulo, v. 14, n. 2, p. 72-8, 2003.

ROCHA, E. F. Reabilitação de pessoas com deficiência: a intervenção em discussão. São Paulo: Editora Roca, 2006.

SASSAKI, R. K. Inclusão: construindo uma sociedade para todos. Rio de Janeiro: Editora EWA, 1997.

SAWAIA, B. As artimanhas da exclusão: análise psicossocial e ética da desigualdade social. Petrópolis: Vozes, 1999. 